\title{
Mathematical modeling of melting during laser heating of metal plate
}

\author{
Mikhail Purin ${ }^{1, *}$, Arkadii Zakharevich ${ }^{1}$, and Nadegda Gutareva ${ }^{1}$ \\ ${ }^{1}$ National Research Tomsk Polytechnic University, 634050 Tomsk, Russia
}

\begin{abstract}
The mathematical modeling of heat transfer processes proceeding together under the conditions of intense phase transformations (melting and metal evaporation) under laser action on a metal plate has been carried out. The analysis of the results has showed that increasing of the laser radiation $\left(\mathrm{q}_{1}\right)$ power leads to acceleration of the melting process. However, it has been found that the change in the melting dynamics with variation of $\mathrm{q}_{1}$ is characteristic only for the plates made of iron and copper. At the same time, it has been found that an increase in $\mathrm{q}_{1}$ does not affect significantly the melting rate of the aluminum plates. It has been established that when the laser is exposed to a plate, zones with large temperature gradients are formed which can cause thermal stresses.
\end{abstract}

\section{Introduction}

The modern industry is linked inextricably with the metal processing operations, such as cutting, welding, micro-remelting and others. Traditionally, they have been performed mechanically on the metalworking machines, however, due to constantly stricter requirements for precision and reliability of the machined parts, a new type of metal processing - laser treatment is becoming very popular and in demand today. The latter has a number of the undoubted advantages [1], such as high accuracy of processing, the ability to work with the complex geometric shapes, the absence of the mechanical damage to the workpiece, etc. The high density of power of the laser in the area of the radiation scatter spot ensures the performance of the process in the combination with the high quality of surfaces treatment.

Laser metals processing operations are linked inextricably with melting and crystallization processes, and the effective studies of the phase transformations are impossible without the computational experiments that allow modeling of the various conditions of action prior to the onset of the costly in-situ experiments.

The mathematical modeling of the processes of metals laser processing is of great interest. The russian scientists V.I. Mazhukin [2-4] and A.A. Samarskii [5,6] have made a significant contribution to the solution of the Stefan problem in the multidimensional formulation, but the methods for solving the Stefan problem proposed earlier are based on the explicit separation of the fusion front, are very complex, require the use of a complex

*Corresponding author: $\underline{\operatorname{mp} 21 @ \text { tpu.ru }}$ 
mathematical apparatus. It should also be noted that, for example, the models [2-4] require the use of the special functions that determine the dynamics of diffusion of the nodes of the difference grid. Their values can only be found from an experiment. For this reason, we can say that the development of a mathematical apparatus for the melting of metals under the conditions of local action of laser radiation is an actual and not solved problem to date.

The aim of the work is mathematical modeling of the processes of heat and mass transfer proceeding together under the conditions of intense phase transformations (melting, evaporation of metal) under the action of a laser.

\section{Physical statement of the problem}

Laser radiation begins to act on the bounded region of the surface of the metal plate at the initial moment of time. As a result, the metal begins to heat up. When the phase transition temperature is reached in the heating region, the melting process is initiated. The fusion front moves deeper into the material. As a result, a heterogeneous structure is formed, consisting of a solid and a liquid phase with the different thermophysical characteristics. As a result of continuous heating, the evaporation process is initiated.

When solving the problem, it has been assumed that the thermal conductivity, heat capacity and density of the metal depend on the position of the melting front. The thermophysical characteristics of the metals under study are given in Table 1 . The heat transfer in the wall (to the metal plate) gas region has been taken into account in the simulation. The thermophysical characteristics of the latter are given in Table 2 .

It has been assumed that the laser beam is directed perpendicular to the surface under consideration, the radiation flux density in the heating zone is distributed regularly.

Table 1. The thermophysical characteristics of metals [7].

\begin{tabular}{|c|c|c|c|c|c|c|}
\hline & \multicolumn{3}{|c|}{ Solid phase } & \multicolumn{3}{c|}{ Fluid phase } \\
\cline { 2 - 7 } & $\begin{array}{c}\mathrm{c}, \\
\mathrm{J} /(\mathrm{kg} \cdot \mathrm{K})\end{array}$ & $\begin{array}{c}\lambda /(\mathrm{m} \cdot \mathrm{K}) \\
\mathrm{Ng} / \mathrm{m}^{3}\end{array}$ & $\begin{array}{c}\mathrm{c}, \\
\mathrm{J} /(\mathrm{kg} \cdot \mathrm{K})\end{array}$ & $\begin{array}{c}\lambda, \\
\mathrm{W} /(\mathrm{m} \cdot \mathrm{K})\end{array}$ & $\begin{array}{c}\rho, \\
\mathrm{kg} / \mathrm{m}^{3}\end{array}$ \\
\hline Aluminum & 951.3 & 240 & 2712 & 1090 & 90,7 & 2368 \\
\hline Iron & 450 & 80 & 7870 & 835 & 39 & 7069 \\
\hline Copper & 385 & 380 & 8933 & 545 & 165,6 & 8000 \\
\hline
\end{tabular}

Table 2. The thermophysical characteristics of gas [8].

\begin{tabular}{|c|c|c|c|}
\hline & $\mathrm{c}, \mathrm{J} /(\mathrm{kg} \cdot \mathrm{K})$ & $\lambda, \mathrm{W} /(\mathrm{m} \cdot \mathrm{K})$ & $\rho, \mathrm{kg} / \mathrm{m}^{3}$ \\
\hline Argon & 519 & 0.0394 & 1.661 \\
\hline
\end{tabular}

Table 3. Heat of fusion, heat of vaporization and the melting point of metals.

\begin{tabular}{|c|c|c|c|}
\hline & $\mathrm{Q}, \mathrm{kJ} / \mathrm{kg}$ & $\mathrm{Q}_{\text {melt }}, \mathrm{kJ} / \mathrm{kg}$ & $\mathrm{T}_{\text {melt }}{ }^{\circ} \mathrm{K}$ \\
\hline Aluminum & 393 & 10900 & 873 \\
\hline Iron & 277 & 6300 & 1810 \\
\hline Copper & 213 & 4800 & 1356 \\
\hline
\end{tabular}

\section{Mathematical formulation of the problem}

The mathematical model of the process under study includes the energy equation for a metal, with taking into account the dependence of the thermophysical characteristics on temperature:

$$
c(T) \rho(T) \frac{\partial T}{\partial t}=\frac{\partial}{\partial x} \lambda(T) \frac{\partial T}{\partial x}+\frac{\partial}{\partial y} \lambda(T) \frac{\partial T}{\partial y}-\frac{Q W}{h_{d}} \delta\left(x_{m e l t}, y_{m e l t}\right) ;
$$


- energy equation for gas:

$$
c \rho \frac{\partial T}{\partial t}=\frac{\partial}{\partial x} \lambda \frac{\partial T}{\partial x}+\frac{\partial}{\partial y} \lambda \frac{\partial T}{\partial y}
$$

here $\mathrm{c}$ is the heat capacity, $\mathrm{J} /(\mathrm{kg} \cdot \mathrm{K}) ; \lambda$ is the coefficient of thermal conductivity, $\mathrm{W} /(\mathrm{m} \cdot \mathrm{K}) ; \rho$ — density, $\quad \mathrm{kg} / \mathrm{m}^{3} ; \mathrm{Q}$ - heat of fusion, $\mathrm{J} / \mathrm{kg} ; \mathrm{W}$ is the mass melting rate of the metal, $\mathrm{kg} /\left(\mathrm{m}^{2} \cdot \mathrm{s}\right) ; \mathrm{h}_{\mathrm{d}}$ is the melting front smearing parameter, $\mathrm{m} ; \delta\left(\mathrm{x}_{\text {melt }}, \mathrm{y}_{\text {melt }}\right)$ is the Dirac delta function. The system (1) - (2) has been solved under the following boundary conditions (Figure 2):

$$
\begin{aligned}
& \mathrm{t}=0 ; 0<\mathrm{x}<1 ; 0<\mathrm{y}<\mathrm{H} ; \mathrm{T}(\mathrm{x}, \mathrm{y})=\mathrm{T}_{\mathrm{s}} \text {; } \\
& 0<\mathrm{x}<\mathrm{l} ; 0<\mathrm{y}<\mathrm{H} ; \mathrm{T}(\mathrm{x}, \mathrm{y})=\mathrm{T}_{\mathrm{g}} \\
& \left.\frac{\partial \mathrm{T}}{\partial \mathrm{x}}\right|_{\mathrm{x}=0} ^{0<\mathrm{y}<\mathrm{H}_{g}}=\left.\frac{\partial \mathrm{T}}{\partial \mathrm{x}}\right|_{\mathrm{x}=\mathrm{l}} ^{0<\mathrm{y}<\mathrm{H}_{g}}=\left.\frac{\partial \mathrm{T}}{\partial \mathrm{y}}\right|_{\mathrm{y}=0} ^{0<x<l}=\left.\frac{\partial \mathrm{T}}{\partial \mathrm{y}}\right|_{\mathrm{y}=H_{g}} ^{0<x<l}=0 ; \\
& \left.\lambda(T) \frac{\partial \mathrm{T}}{\partial \mathrm{y}}\right|_{\mathrm{y}=\mathrm{H}} ^{0<x<\mathrm{x}_{1}}=\left.\lambda_{g} \frac{\partial \mathrm{T}}{\partial \mathrm{y}}\right|_{\mathrm{y}=\mathrm{H}} ^{0<x<\mathrm{x}_{1}} ; \\
& \left.\lambda(T) \frac{\partial \mathrm{T}}{\partial \mathrm{y}}\right|_{\mathrm{y}=\mathrm{H}} ^{\mathrm{x}_{1}<x<\mathrm{x}_{2}}=\left.\lambda_{g} \frac{\partial \mathrm{T}}{\partial \mathrm{y}}\right|_{\mathrm{y}=\mathrm{H}} ^{\mathrm{x}_{1}<x<\mathrm{x}_{2}}+q-W_{i s p} \cdot Q_{i s p} ; \\
& \left.\lambda(T) \frac{\partial \mathrm{T}}{\partial \mathrm{y}}\right|_{\mathrm{y}=\mathrm{H}} ^{\mathrm{x}_{2}<x<\mathrm{l}}=\left.\lambda_{g} \frac{\partial \mathrm{T}}{\partial \mathrm{y}}\right|_{\mathrm{y}=\mathrm{H}} ^{\mathrm{x}_{2}<x<\mathrm{l}} ;
\end{aligned}
$$

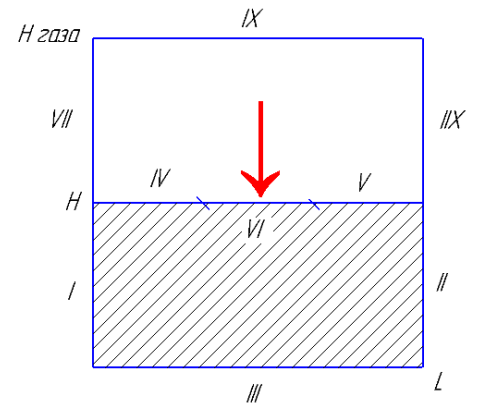

Fig. 2. Scope of the problem.

The problem has been solved by the method of finite differences with using an implicit four-point difference template with the use of the discontinuous coefficients $[9,10]$. The nonstationary multidimensional Stefan problem has been solved by the method of implicit separation of the fusion front [11].

\section{Results}

The numerical studies have been carried out for aluminum, copper and iron plates. The choice of these metals is due to their wide application in the industries requiring high accuracy and reliability of material processing.

Figure 3 shows the melting times of the plates of iron, copper and aluminum. The analysis of the dependences of Fig. 3 shows that an increase in the power of the heat flux leads to a decrease in the melting time of the iron and copper plates, that is, to an increase in their melting rate. Thus, with an increase in the heat flux from 2 to $4.5 \mathrm{MW} / \mathrm{m}^{2}$, the melting time of the iron and copper plates decreases from 210 to 150 and from 150 to 75 
seconds, respectively. Other regularities are manifested when the aluminum plate melts. The increase in the power of the heat flux does not change practically the melting time of the sample. The latter is explained by the significant differences in their heat capacities: the heat capacity of aluminum is more than 2 times higher than the heat capacity of iron and almost 3 times higher than the heat capacity of copper (Table 1).

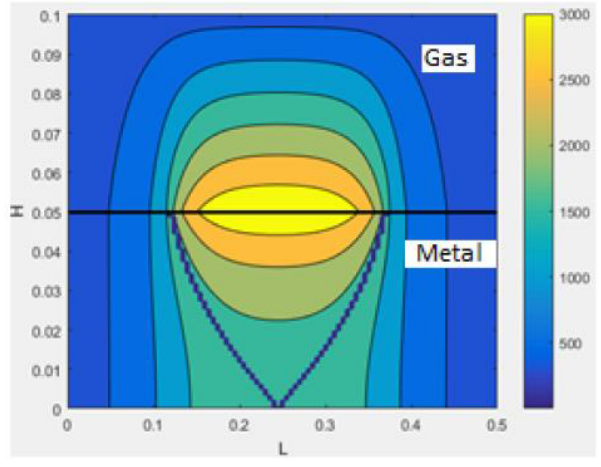

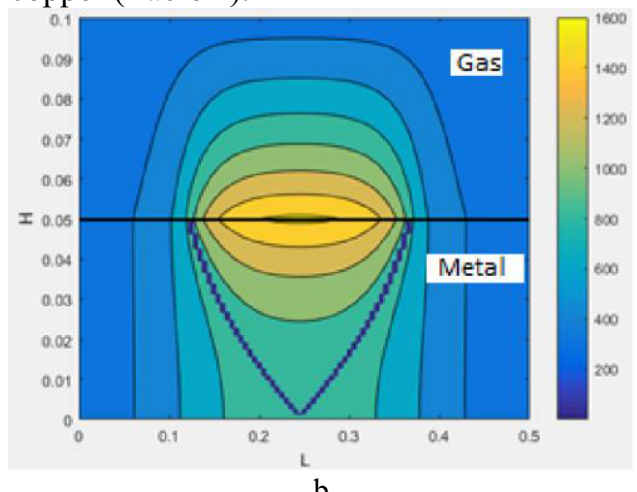

b

Fig. 3. The typical temperature field in the "gas-metal" system: an iron plate (Fig. 4, a); an aluminum plate (Figure 4, b).

Figure 4 shows the typical temperature fields in the "gas-metal" system. One can note the formation of a characteristic bath of the molten metal in the laser action zone. The high temperature gradients are clearly visible, illustrating the possibility of forming zones of local thermal stresses in high-energy laser processing of metals. The latter can lead to the destruction of the metal blank. Also, the analysis of the temperature fields shows that in the aluminum blank, the temperature gradients are substantially less than in the iron blank. The latter is due to the higher thermal conductivity (Table 1) of Al compared to Fe. This can lead to high energy costs for laser processing of the aluminum surfaces, due to intensive heat removal through aluminum.

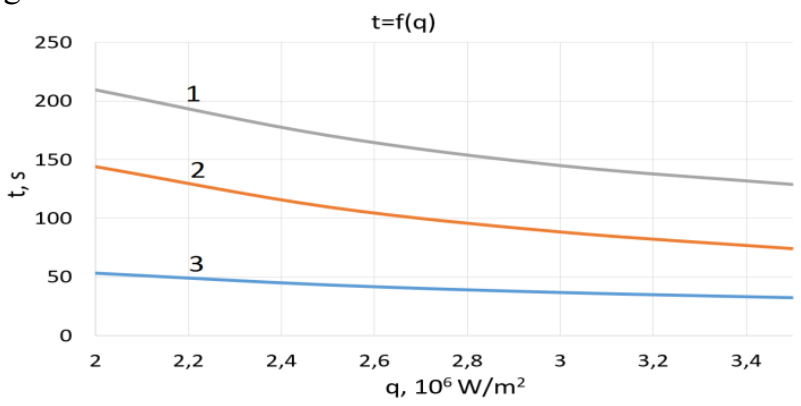

Fig. 4. Dependence of the time t of melting of plates from different metals on the magnitude of the incident heat flux q.

\section{Conclusion}

According to the results of the mathematical modeling of laser heating of a metal plate, the integral characteristics of the melting process of a metal have been established. It has been shown that a change in the radiation flux density can affect the melting conditions of the metal plates. However, the degree of influence is different and depends essentially on the material. So increasing the laser radiation power from 2 to $4.5 \mathrm{MW} / \mathrm{m}^{2}$ (approximately 2 
times) reduces the melting time of iron from 210 to 150 seconds (by 25\%) and a copper plate from 150 to 75 seconds (by 50\%). At the same time, the results of the numerical analysis have showed that the same increase in the radiation flux density does not have a significant effect on the time characteristics of aluminum melting (a decrease of $t_{\text {пл }}$ is not more than 10\%). The latter is most likely due to the high heat capacity and thermal conductivity of aluminum. As a result of numerical simulation, it has been established formation in the plate of the high local temperature gradients in the zone of laser heating. Accordingly, it can reasonably be assumed that laser heating may cause the local temperature stresses leading to the destruction of the metal.

The work was supported by the scientific schools grant NSH-7538-2016.8.

\section{References}

1. A.G. Grigoriants, A.A. Sokolov, A.A. Grigor'yants, Laser cutting of metals. (Higher education. Shk., 1988)

2. V.I. Mazhukin, A.V. Shapranov, Mathematical modeling of the processes of heating and melting metals (Part I. Model and computational algorithm, 2012)

3. V.I. Mazhukin, A.V. Shapranov, Molecular-dynamic modeling of heating and melting of metals (Part II. Computational Experiment, Preprints of IPM, 2012)

4. O.N. Koroleva, V.I. Mazhukin, Zh. Vychisl, Math. And Math. Fiz. 46, (2006)

5. A.A. Samarsky, P.N. Vabishchevich, Computational heat transfer (Editorial URSS, 2003)

6. A.A. Samarskii, B.D. Moiseenko, Zh. Vychisl, Math. and Math. Fiz. 5, (1965)

7. V.S. Chirkin, Thermophysical properties of materials (FIZMATGIZ, 1959).

8. N.B. Vargaftik, Reference book on thermophysical properties of gases and liquid. (Moscow, 1972).

9. S.V. Syrodoy, N.Y. Gutareva, R.I. Taburchinov, MATEC Web Conf. 72, (2016)

10. S.V. Syrodoy, N.Y. Gutareva, R.I. Taburchinov, MATEC Web Conf. 72, (2016)

11. S.V. Syrodoy, N.Y. Gutareva, K. A. Bugaeva, MATEC Web Conf. 72, (2016) 